\title{
Proceedings of the 56th Annual meeting of Eastern Region
}

\section{Special Lecture}

\author{
Kawasaki, October 25, 2004
}

1. Rattus rattus and zoonoses in urban buildings

\section{Contributed Papers}

1. Ecology of mosquitoes inhabiting a well-wooded park in urban area

2. Collection of adult mosquitoes at eastern Hokkaido, by dry ice-trap

3. Survey of mosquitoes inhabiting residential area in Saitama prefecture ... Nomoto, K. and Urabe, K.

4. Survey of the habitat on mosquito larvae in Kawasaki city

..................Sugimoto, N., Sano, K., Sato, S., Sugimoto, T. and Sato, H.

5. Study of distribution and seasonal occurrence on the mosquitoes in Kawasaki city

Sato, H., Sugimoto, N. and Sano, K.

6. Surveillance of mosquito habitats in Kamakura, Zushi and Hayama areas

Koizumi, T. and Shinjo, G.

7. Surveillance of mosquitoes in Yachiyo and Sakura city in 2004

Shirai, Y.

8. Surveillance study of mosquitoes in Chiba prefecture

Fujimagari, M., Ogawa, T., Hosaka, H. and Kaiho, I.

9. Did it lead to the mass occurrence of Culex tritaeniorhynchus in the hot summer 2004?.

10. New species of Ascogregarina from Aedes and Armigeres mosquitoes in Japan

Kobayashi, M., Roychoudhury, S., Higa, Y., Nihei, N., Isawa, H., Sasaki, T., Sawabe, K. and Tsuda, Y.

11. Molecular discrimination of Culex pipiens pallens and C. p. form molestus collected in Japan

..........Kasai, S., Komagata, O., Shono, T., Tomita, T., Sawabe, K., Higa, Y., Tsuda, Y., Motoki, M., Takahashi, T., Tanikawa, T., Yoshida, M. and Kobayashi, M.

12. Comprehensive study cytochrome P450s for Culex mosquitoes .Komagata, O., Kasai, S. and Tomita, T.

13. Detection of West Nile virus from field-collected mosquitoes in Japan, 2004 ..Sawabe, K., Isawa, H., Hoshino, K., Sasaki, T., Fukushi, K., Miyagawa, K., Tamura, Y., Sato, H.,Tsuda, Y., Higa, Y. and Kobayashi, M.

14. Study on control of Culex pipiens molestus from an underground septic tank Shinjo, G. and Koizumi, T.

15. Traditional control methods of medically important insect and mites (13) Kabi, Hinawa and Dannou

16. Night observation of Japanese cockroaches in urban green 
17. Adaptation of the German cockroaches to the harborages made of various woods

18. The prevalence of $k d r$ gene in field colonies of the German cockroach .Tomita, T., Kasai, S., Komagata, O. and Tanikawa, T.

19. Holotype of Sarcophaga asahinai Kano, 1962 is considered to be an abnormal form with vestigial aedeagus

20. The present condition of Sasa collection (Chironomidae)

21. The summer activity of the new generation of Haemaphysalis flava adults, with special reference to behavioral diapause

22. The attractant effect of geranyl propionate for monitoring the population density of pyroglyphid mite in house dust

$$
\text { Hashimoto, T., Yoshikawa, A., Tanaka, I., }
$$
Uchida, A. and Kawakami, Y.

23. Measures and perspectives on rats control

24. An example of a person bitten by the roof rat 